\title{
HADDOCK ON THE PORCUPINE BANK, SEPTEMBER I944
}

\author{
By C. F. Hickling, M.A. \\ Colonial Office
}

(Text-figs. I-6)

In September 1944 I wished to see at first hand the state of the fishing grounds after five years of much reduced fishing due to the war-time requisitioning of the fishing fleet. I sailed from Cardiff on I8 September on the steamtrawler Iwate, by courtesy of Messrs Neale and West of Cardiff, and of the skipper, Mr Walter Rymer. I would here express my thanks to Messrs Neale and West, and to Skipper Rymer and Mr W. Payne, mate of the Iwate, for their kindness and hospitality, and for all they did to help me.

The Iwate steamed to the Porcupine Bank, and put in some I4O hr. of fishing time between 20 and 28 September. The depths worked were between I 20 and I 80 fathoms, but chiefly between 140 and I 60 fathoms. The ship landed some II $25 \mathrm{cwt}$. of fish on 2 October, including $524 \mathrm{cwt}$. of hake and $355 \mathrm{cwt}$. of haddock.

I measured samples of the hake and haddock caught, and made a collection of haddock scale samples. The present paper deals with the haddock. The scales were read for age estimation by Mr W. Main, of the Scottish Home Department's technical staff, and I will here thank Dr R. S. Clark, Director of the Fisheries Laboratory at Aberdeen, and Mr Main, for their help. The counting of the sclerites in the scales, and the calculation of the growth rates, however, were my work, and I am responsible for the results here described. My secretary, Mrs F. R. Kellen, gave me valuable help in the preparation and examination of the scales.

\section{The Porcupine Bank}

This Bank lies in the Atlantic, about I20 miles west of Ireland. The shallowest water on the Bank is 80 fathoms, but the extent of the Bank, as demarcated by the roo-fathom line, is some 45 miles long by 15 miles wide. Unlike Rockall Bank, which is entirely separated from the Continental Shelf, the Porcupine is a knoll on the westerly edge of the Continental Shelf itself. Between the Bank and the Irish coast the water deepens to about 185 fathoms.

Most of the fishing is done on the northern slopes of the Bank; the top of the Bank is too rough for much fishing except in fine weather. Though the species chiefly fished for is the hake, there are always haddock on the upper slopes of the bank, which are valued as giving variety to the catches made. 
These haddock form an outpost of a northerly species of fish in the midst of an area dominated by a southerly species, hake. It is probable that, as on the Rockall Bank (Hickling, I928a), colder water on the Porcupine favours the local establishment of a haddock population. The only hydrographical section across the Porcupine which I have found, made in May 1905 (Conseil International, 1905), confirms the existence of this slightly colder water. This section is reproduced in Fig. I.

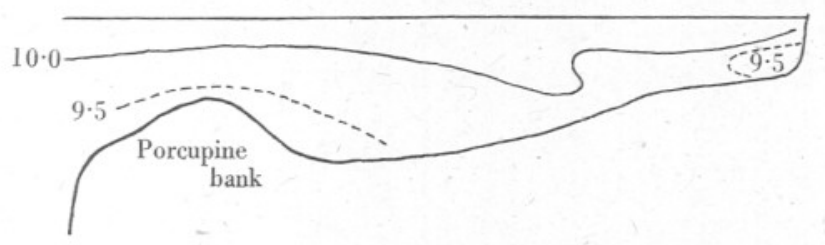

Fig. I. Hydrographical section across the Porcupine Bank, May 1905. Isotherms in ${ }^{\circ} \mathrm{C}$.

The results of my cruise show clearly that haddock were most plentiful in the shallower water, whereas hake were most abundant in the deeper water. Table I summarizes the average number of baskets of hake and haddock respectively taken per haul of $4 \frac{1}{2} \mathrm{hr}$. at each of four depths.

\begin{tabular}{ccc}
\multicolumn{3}{c}{ TABLE I } \\
Depth & & \\
fathoms & Baskets of hake & Baskets of haddock \\
I25 & 2 I & 23 \\
I45 & 42 & I4 \\
I50 & 40 & I2 \\
I85 & 33 & 6
\end{tabular}

As a result of a survey of the fishing grounds to the west of Scotland (Hickling, I928b) I showed that haddock were not caught in water deeper than 220 fathoms, whereas hake were caught as deep as 400 fathoms. Since the sea bed, connecting the Porcupine Bank with the Irish coast, is not deeper than 185 fathoms, it is debatable whether the stock of haddock on the Porcupine is continuous with the stock caught close in to the Irish coast and in the bays there. Raitt (1939) says the haddock 'is not of general occurrence, but is confined to certain definite locations'. 'There is no continuity of occurrence between these different regions. Beyond the limit of, approximately, the 200 metre depth contour, in each separate area, the species is not found.' 'There exists a number of independent stocks of haddock, isolated from each other geographically and bathymetrically, each self-contained, and each selfsupporting.' In terms of Raitt's definition, the Porcupine haddock possibly form a distinct stock, and some confirmation of this may be got from an inspection of the abundance of haddock in each statistical rectangle in the area to the west of Ireland. I have taken 1938 as a sample year, and have 
extracted from the note-books of the collectors of statistics at Milford Haven for that year all voyages made by the Milford trawlers to the west of Ireland (including the Porcupine Bank). Thence I have calculated the average weight of haddock caught per $100 \mathrm{hr}$. fishing in each statistical rectangle.

In Fig. 2 the figures represent in each rectangle (the boundaries of which are not shown) the average weight of haddock per $100 \mathrm{hr}$. fishing. The approximate area worked by the Iwate is shown by an arrowed line.

Haddock were most abundant close in to the west and south-west coasts of Ireland, but there was a decided secondary increase of abundance at the Porcupine. The apparent capture of haddock in the deep water to the south

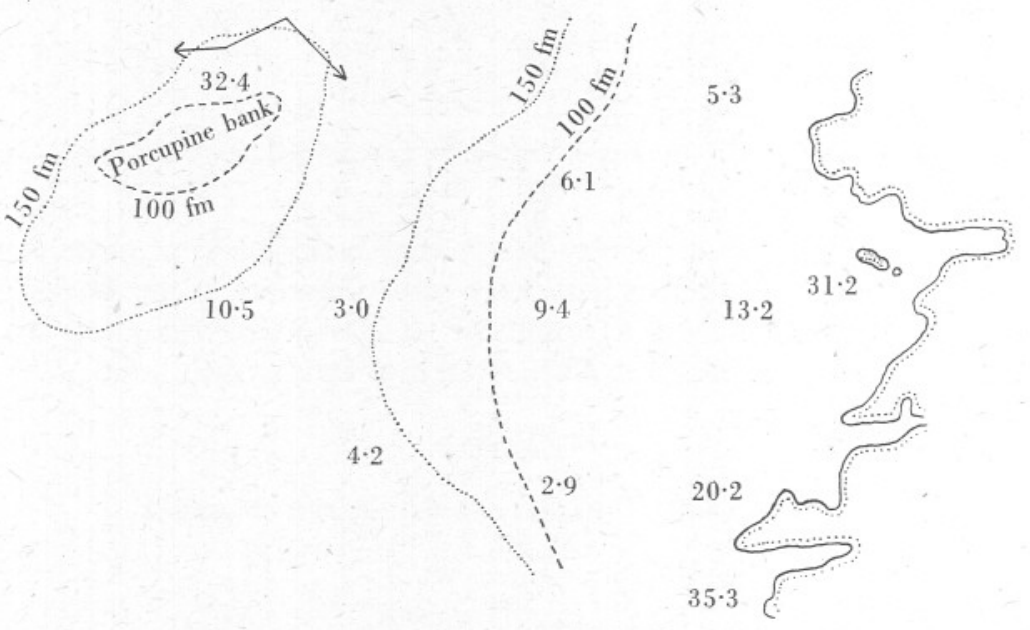

Fig. 2. Catch of haddock per $100 \mathrm{hr}$. fishing in each statistical rectangle to the west of Ireland, $193 \delta$.

and south-east of the Porcupine may be misleading, for the collectors' notebooks necessarily allot the whole of a catch of a ship to that area where most of the fishing took place. A trawler which fishes most of her voyage in the deep water, but which has a day's work in shallower water on the way out or on the way home (a very common practice) will have the whole of her catch allotted to the deep-water ground, and this probably accounts for most of the haddock apparently caught in the deep water. Bearing this in mind, the data in Fig. 2 give some reason for believing that the haddock on the Porcupine form to a large degree a self-contained stock, though doubtless with much exchange with the haddock of the Irish coast.

\section{StaTistics}

The Porcupine Bank was worked to a considerable extent by Milford trawlers in the pre-war years, though not to as great an extent as by ships from Cardiff. The amount of fishing done on the Porcupine varied, of course, with the yield 
of other grounds. The trawlers would not visit this distant ground when better results were to be got nearer home. Table II gives the number of hours' fishing, and the average weight of haddock per Ioo hr. fishing, by Milford steamtrawlers in August, September and October 1935-1940, and 1944. For the years 1938 to 1940 the catches are distinguished into large, medium and small haddock. The data are extracted from the note-books of the collectors of statistics at Milford Haven.

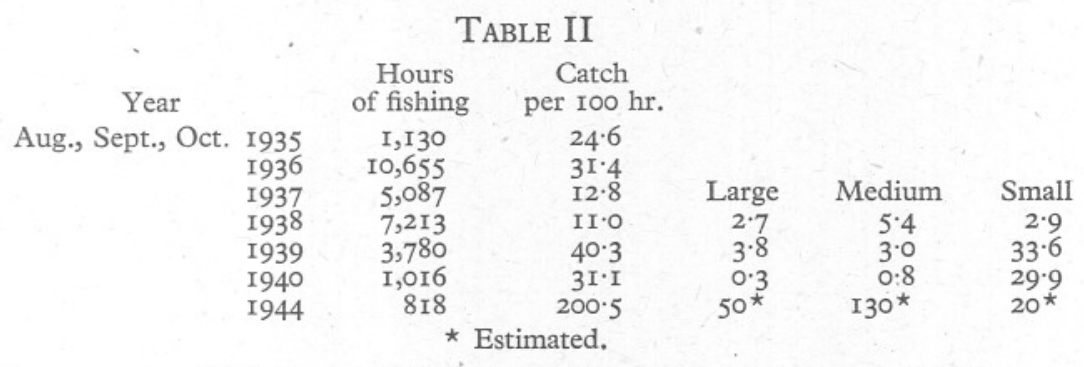

The amount of fishing by Milford trawlers varied widely in the four years I935-8; in 1939, 1940 and 1944 the war reduced the amount of fishing. In spite of the danger of attack by enemy aircraft, trawlers continued to work the Porcupine throughout I940 until, in December 1940, a Cardiff trawler was bombed and sunk with loss of life. From that date until September 1944, no fishing took place on the Porcupine. My voyage on the Iwate was therefore among the first to this ground after a rest of four years.

The abundance of haddock also varied widely. The years 1935 and 1936 showed a comparative abundance of haddock, whereas the years 1937 and I 938 showed a great scarcity. The years 1939 and 1940 were again years of comparative abundance, and the table shows that this was wholly due to an influx into the catches of 'small' haddock.

In I944, after a four years' respite from trawling, haddock were five times as abundant as in 1939, the best pre-war year in this series. From the measurements given later, it is estimated that these heavy catches were largely in the pre-war categories of large and medium, and in the proportion of roughly 3 to I medium to large haddock. Few 'small' haddock were caught.

\section{The Haddock CAUght IN SePtember I944}

\section{Length and age}

All the haddock examined during my voyage were in excellent condition, their livers creamy with fat. The gonads were in the spent-recovering condition, few showing any advanced recovery. Feeding was heavy, chiefly on echinoderms and shell-fish, though some crustacea, including euphausiids, were noted.

In Fig. 3 are given the measurements, grouped by $5-\mathrm{cm}$., of the male and female haddock caught. The frequency curves for both sexes are strongly 
bimodal; in both males and females the first mode is at about $43 \mathrm{~cm}$., but the second mode is at about $56 \mathrm{~cm}$. in males and $58 \mathrm{~cm}$. in females. Females are more numerous among the largest fish; in fact, the largest male was $63.3 \mathrm{~cm}$. long, the largest female $67.0 \mathrm{~cm}$. Females were also more abundant than males among the smaller fish. Measurements of Porcupine haddock, made on the Milford Market in January 1945, confirm these measurements made at sea in September. In Fig. 4 the measurements are grouped according

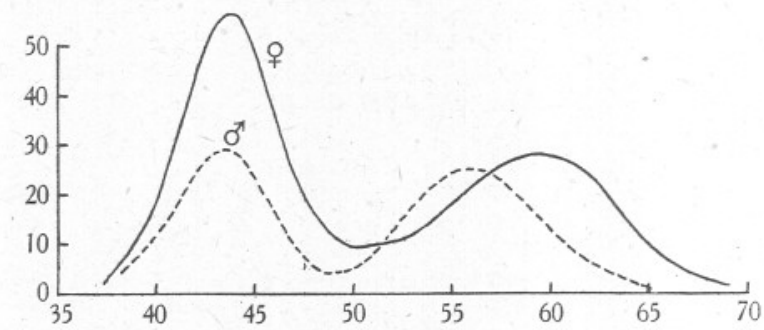

$\mathrm{cm}$.

Fig. 3. Frequency distribution of measurements of male and female haddock on the Porcupine Bank, September 1944 .

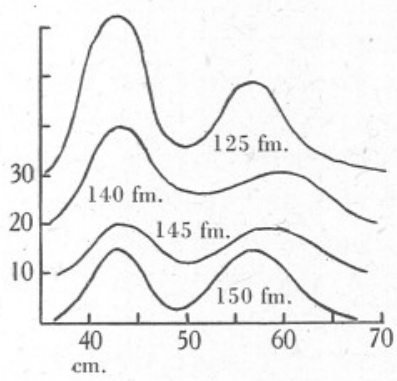

Fig. 4 .

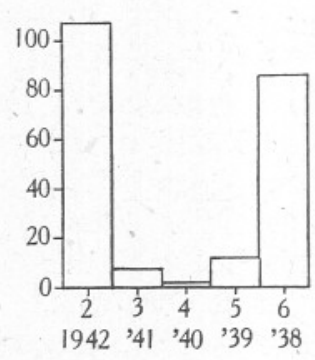

Fig. 5 .

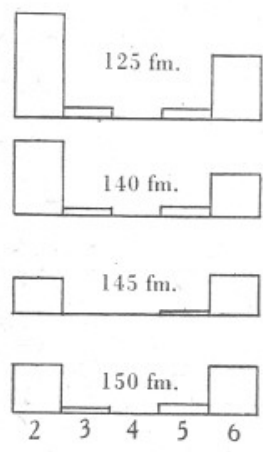

Fig. 6.

Fig. 4. The effect of increasing depth on the length-distribution of haddock on the Porcupine Bank, September 1944.

Fig. 5. The age distribution of the haddock on the Porcupine Bank, September 1944.

Fig. 6. The effect of increasing depth on the age distribution of haddock on the Porcupine Bank, September 1944 .

to depth, both sexes being combined. Again the curve takes a bimodal shape, but it will be noted that, whereas in 125 and 140 fathoms the mode at $43 \mathrm{~cm}$. is dominant, in 145 and 150 fathoms the two modes are about equal. There is therefore a decided tendency for the larger fish to be found in the deeper water.

The sex ratio shows no definite tendency with increase of depth. Females always predominated. Some I30 females, but only 80 males, were found among the fish measured. 
In Fig. 5 is shown the frequency distribution of the year classes. It will be seen that two year classes, the $2+$ and the $6+$, spawned respectively in I942 and I938, dominate all others. In fact, the broods of I939, I940 and I94I are almost unrepresented.

These findings also were confirmed in January I945, on a sample of haddock from the Porcupine, examined on the Fish Market at Milford Haven. Below are given the age distribution of the haddock samples examined on the Porcupine Bank in September I944, and on Milford Fish Market in January I945:

$\begin{array}{lccccc} & 2+ & 3+ & 4+ & 5+ & 6+ \\ \text { September I944 } & \text { 107 } & 8 & 2 & \text { 12 } & 85 \\ \text { January I945 } & \text { I88 } & 7 & 7 & 28 & 78\end{array}$

In the January samples the narrow winter sclerites are clearly visible at the margin of the scales, and in one or two female fish, in which slovenly gutting had allowed the ovary to remain, the latter was seen to be ripening, even in fish as small as $43 \mathrm{~cm}$.

In Fig. 6 the samples are grouped in order of depth, and it appears that the younger fish are found more in the shallower water, thus confirming the evidence of Fig. 5. The larger and older fish obviously tended to occupy the deeper water, the younger and smaller fish the shallower.

\section{The Sclerite Number}

On a large number of the scales of both sexes in the two dominant agegroups the number of sclerites in each annual scale zone were counted. The average numbers are given in Table III.

\section{TABLE III}

\begin{tabular}{cccccccc}
\multicolumn{7}{c}{ Average number of sclerites in brood } \\
I938 & 32 & 2 & 3 & 4 & 5 & 6 \\
1942 & 32 & 24 & I5 & I2 & 9 & 7
\end{tabular}

I tested these means statistically, and found that except in the first year's growth among the 1942 brood, there was nowhere any significant difference between the numbers of sclerites in males and females. In the exception, the males had an average of 34 sclerites in the first zone, the females 30 , and the difference was significant.

There is no significant difference between the number of sclerites in the first and second scale zones of 2-year-old and 6-year-old fish (the I942 and I938 classes).

These sclerite numbers may be compared (Table IV) with those found in the scales of haddock from other regions, as given by Thompson (I928).

In the first scale zone the Porcupine haddock had more sclerites than in any of the regions listed, the Irish coast coming nearest. In the second zone 


\begin{tabular}{|c|c|c|c|c|c|c|}
\hline ' & \multicolumn{5}{|c|}{ Year } & ' \\
\hline Region & I & 2 & 3 & 4 & 5 & 6 \\
\hline North Sea & 22 & I $5 \frac{1}{2}$ & 12 & 9 & $8 \frac{1}{2}$ & 8 \\
\hline Norway & 20 & I4 & $13 \frac{1}{2}$ & 13 & 9 & 8 \\
\hline Faroe & 22 & 19 & I6 $\frac{1}{2}$ & I4. & II $\frac{1}{2}$ & IO \\
\hline Iceland & $20 \frac{1}{2}$ & $20 \frac{1}{2}$ & 16 & I $4 \frac{1}{2}$ & $\mathrm{I}_{4}$ & I4 \\
\hline Nantucket, U.S.A. & 23 & 24 & I8 & I5 & - & - \\
\hline Irish coast & 26 & I9 & I6 & I $3 \frac{1}{2}$ & I2 & IO $\frac{1}{2}$ \\
\hline Porcupine & 32 & $22 \frac{1}{2}$ & I5 & 12 & 9 & 7 \\
\hline
\end{tabular}

the Porcupine haddock were only exceeded by those from Nantucket, U.S.A. But in the third zone they had a sclerite number less than in all regions except the North Sea and Norway, and in the later zones had almost the fewest sclerites in any region.

A false ring appeared fairly regularly between the 9th and I9th sclerites, with the average at the I4th sclerite. Thompson (I922) states that in North Sea haddock this false winter ring appears at the 7 th to the 12 th sclerites. Thompson says that this false winter ring appears in many haddock, 'presumably those which...have taken to the bottom in fairly deep water and encountered a sharp change of temperature'. 'The young haddock must be accommodating itself to the new conditions it may meet on seeking the bottom.'

\section{The Growth Rate}

Below are given the average lengths, in cm., of the successive year classes in my Porcupine samples. There were, however, very few specimens of $3+, 4+$ and $5+$ fish on which to base an average (see Fig. 6). They are compared with the average lengths of fish in each class in other regions, as listed by Thompson (1928). But since my samples were collected in September, when wide sclerites were still being laid down at the margin of the scale and when therefore the year's growth had not finished, in Table V my $2+$ fish are compared with the 3 -year fish in the other regions.

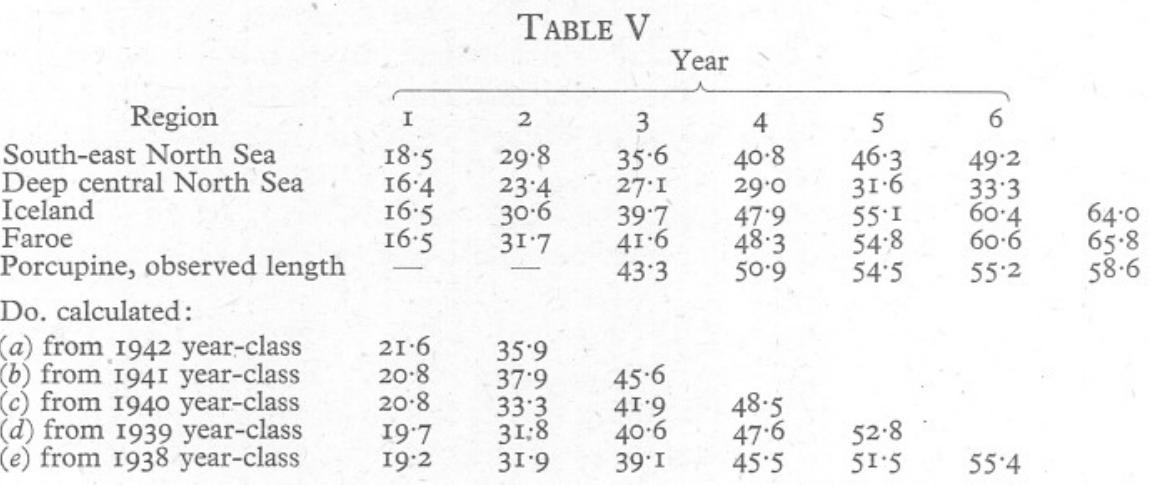


The table shows that the average length of the $2+$ haddock on the Porcupine was already greater than that even of the Faroe haddock, and the same is true of the $3+$ haddock. But from the $4+$ fish onwards, the Porcupine haddock were smaller than both the Faroe and the Iceland haddock. But they were much larger than the fastest-growing North Sea haddock. The figures suggest, in conjunction with the sclerite numbers, that the Porcupine haddock grow more rapidly, during the first four years of life, than any other stock of haddock, but that growth then slows down, so that it is overtaken by the steadier rapid growth of the Iceland and Faroe fish.

These findings are confirmed by the calculated rates of growth, also given in the above table. The calculated length attained at the end of each winter apparently increases from the older fish (the 1938 class) to the younger (the I942 year class). This is almost certainly due to Lee's phenomenon, and the youngest year-class will give the best estimate. The table shows that the Porcupine haddock reach an average length of about $22 \mathrm{~cm}$. at the end of their first complete yéar; and about $36 \mathrm{~cm}$. at the end of their second complete year.

The false winter ring, which appears on a large number of these scales, is formed when the fish has a calculated average length of II.5 cm. in the $2+$ fish, of $10.0 \mathrm{~cm}$. in the $5+$ fish, and of $9.4 \mathrm{~cm}$. in the $6+$ fish. Again allowing for Lee's phenomenon, these figures suggest that the Porcupine haddock take up a bottom-living habit at a length of about $\mathrm{I} 2-\mathrm{I} 3 \mathrm{~cm}$., thus at a somewhat larger size than those in the North Sea, which according to Thompson (I922) take up this habit at a length of about II $\mathrm{cm}$.

Haddock become legally marketable at a length of $9 \frac{1}{2}$ in., or about $24 \mathrm{~cm}$. The Porcupine haddock therefore become marketable in their second year of life, and the sudden big increase in the abundance of small haddock in I939 and I940 (Table II) was clearly due to the growth to marketable size of the 1938 year class, which is still so strongly represented in my samples. Maturity sets in, in the haddock, in the third year of life, and this rich yearclass would therefore spawn in full strength in 1942. The extraordinary abundance of haddock on the Porcupine in 1944 is therefore due to a good year class, that of 1938 , growing up, after its second year, free from fishingmortality, and in turn spawning, in 1942, a year-class which had also suffered no mortality due to fishing.

\section{Discussion}

Bückmann (I939) shows that, in the German Bight, in the years from I924 to 1938 , the growth rate of the plaice was inversely proportional to the density of the stock of fish on the grounds. Fischer (1939) found that the thinning of the stock of plaice and flounder in the Baltic, due to intensive fishing, resulted in a more rapid rate of growth of the survivors. Still more relevantly, Raitt (I939) shows that, in the North Sea haddock, 'there is close agreement between these variations in growth rate and the degree of brood density, the poorer the brood the less the competition for available food and the faster 
the rate of growth. It follows that increased depletion will itself have had a similar tendency, the poorer the brood the faster its growth, the faster the growth the quicker its depletion, and the quicker the depletion the less competition for the upcoming stock and the greater its growth'.

But it is clear that the converse of these findings do not apply to the haddock of the Porcupine Bank. The complete cessation of fishing there at the end of I940 saw the Bank populated with abundant small haddock (Table II). This brood, spawned in 1938 , continued to grow for 4 years without depletion due to fishing, and it was joined, in 1942, by another good brood, the broods of I939-4I having failed. Consequently, by the time fishing on the Porcupine was resumed in September 1944, the Bank carried a haddock population five times as dense as in the best of the years immediately before the war, and indeed was the best fishing for haddock ever known there. Yet when the calculated growth-rate of the 1938 brood in its first 2 years of life is compared with that of the 1942 brood, as in Table V, it is plain that, even allowing for the effect of Lee's phenomenon, the 1942 brood, growing up under comparatively crowded conditions, grew no less rapidly than that of 1938 , and this is confirmed by the sclerite numbers (Table IV). Moreover, all the haddock were in excellent condition: these facts do not suggest that competition for the available food had stunted the growth of this much denser population of haddock.

It may be that the 4 years' cessation of trawling allowed the bottom fauna on which these haddock feed to increase in abundance, yet this fauna would throughout have been cropped by an increasing stock of fish.

\section{SUMMARY}

I. It is suggested that the population of haddock (Gadus aeglefinus L.) on the Porcupine Bank is largely a self-contained stock.

2. This stock had complete immunity from trawling from December I940, to September 1944.

3. In I 939 and I 940 there was an abundance of small haddock in this stock, due to the good brood of 1938. In 1944, this brood was still very abundant, and was then joined by the good brood of 1942 .

4. These two good broods, growing up immune from fishing mortality, caused the Porcupine Bank to carry, in I944, the densest stock of haddock ever experienced there.

5. The average number of sclerites in the first zone of the scales of these fish is the highest recorded in any region. It is still high in the second zone, but in the later zones falls below that found in the scales of haddock from other regions.

6. The growth rate was faster, in the first four years of life, than even that of Iceland and Faroe haddock, but in the later years it fell behind these, though still superior to the growth rate of the North Sea haddock. 
7. The expectation that this greatly increased stock of haddock, due to the war-time cessation of fishing, would show a slowing in its rate of growth, due to intensified competition for the available food, is not supported by the facts.

\section{REFERENCES}

BückmanN, A., I939. Zur Frage der Beziehungen zwischen Befischung und Ertrag. Rapp. Proc. Verb. Cons. Int. Explor. Mer, Vol. cx, pp. 2 I-30.

Conseil Permanent International pour L'Exploration De LA Mer. Bulletin des résultats acquis pendant les courses périodiques. Année 1904-1905. Copenhagen, I905. FISCHER, E., I939. Der Einfluss der Fischerei auf den Schollen- und Flunderbestand in der Ostsee. Rapp. Proc. Verb. Cons. Int. Explor. Mer, Vol. cx, pp. 97-I05.

Hickling, C. F., I928a. The Fleetwood exploratory voyages for hake. fourn. Cons. Int. Explor. Mer, Vol. III, pp. 70-89.

- I $928 b$. The exploratory voyages of the Florence Brierley. Notes on the fish recorded. Ann. Mag. Nat. Hist., Ser. Io, Vol. II, pp. I96-209.

RAITT, D. S., I939. The rate of mortality of the haddock of the North Sea stock, 1919-1938. Rapp. Proc. Verb. Cons. Int. Explor. Mer, Vol. cx, pp. 65-79.

Thompson, H., 1922. Problems in haddock biology. I. Preliminary report. Fisheries, Scotland, Sci. Invest. I922, No. v (May I923).

— I928. Haddock biology. V. General features in the biology of the Haddock (Gadus aeglefinus L.) in Icelandic waters in the period 1903-26. Fisheries, Scotland, Sci. Invest., I928, No. v. 